\title{
Plasmid-mediated quinolone resistance; interactions between human, animal, and environmental ecologies
}

\author{
Laurent Poirel $^{1}$, Vincent Cattoir ${ }^{2}$ and Patrice Nordmann ${ }^{1}$ \\ " INSERM U914 "Emerging Resistance to Antibiotics", Service de Bactériologie-Virologie, hôpital de Bicêtre, Assistance Publique/Hôpitaux de Paris, Faculté de \\ Médecine Paris-Sud, Université Paris XI, K.-Bicêtre, France \\ ${ }^{2}$ Equipe EA2128 Interactions Hôtes et Microorganismes des Epithéliums, Faculté de Médecine de Caen, Université Caen Basse Normandie, Caen, France
}

\section{Edited by:}

Stefania Stefani, University of

Catania, Italy

\section{Reviewed by:}

José Manuel Rodriguez-Martínez,

University of Seville, Spain

George Jacoby, Lahey Clinic, USA

*Correspondence:

Laurent Poirel, Service de

Bactériologie-Virologie-Hygiène,

Hôpital de Bicêtre, Université Paris XI,

78 rue du Général Leclerc, 94275

K.-Bicêtre, France.

e-mail: laurent.poirel@bct.aphp.fr
Resistance to quinolones and fluoroquinolones is being increasingly reported among human but also veterinary isolates during the last two to three decades, very likely as a consequence of the large clinical usage of those antibiotics. Even if the principle mechanisms of resistance to quinolones are chromosome-encoded, due to modifications of molecular targets (DNA gyrase and topoisomerase IV), decreased outer-membrane permeability (porin defect), and overexpression of naturally occurring efflux, the emergence of plasmidmediated quinolone resistance (PMOR) has been reported since 1998. Although these PMOR determinants confer low-level resistance to quinolones and/or fluoroquinolones, they are a favorable background for selection of additional chromosome-encoded quinolone resistance mechanisms. Different transferable mechanisms have been identified, corresponding to the production of Qnr proteins, of the aminoglycoside acetyltransferase AAC $\left(6^{\prime}\right)-\mathrm{lb}$-cr, or of the QepA-type or OqxAB-type efflux pumps. Onr proteins protect target enzymes (DNA gyrase and type IV topoisomerase) from quinolone inhibition. The AAC(6')lb-cr determinant acetylates several fluoroquinolones, such as norfloxacin and ciprofloxacin. Finally, the QepA and OqxAB efflux pumps extrude fluoroquinolones from the bacterial cell. A series of studies have identified the environment to be a reservoir of PMQR genes, with farm animals and aquatic habitats being significantly involved. In addition, the origin of the qnr genes has been identified, corresponding to the waterborne species Shewanella sp. Altogether, the recent observations suggest that the aquatic environment might constitute the original source of PMQR genes, that would secondly spread among animal or human isolates.

Keywords: Quinolone resistance, Qnr, plasmid, efflux pump

\section{INTRODUCTION}

Quinolones are fully synthetic and bactericidal antibacterial agents used widely in both human and veterinary medicine. The clinically available quinolones have been classified into several generations based of their spectrum of activity (Ball, 2000). The first generation quinolone (Q1G), nalidixic acid, has been discovered in 1962 (Lesher et al., 1962). Other Q1G, such as pipemidic acid and oxolinic acid, had been developed, the latter being used for in veterinary medicine. The quinolones of the second generation are made of addition of a fluorine atom at position C- 6 to the quinolone nucleus, yielding to the fluoroquinolones (FQ; Paton and Reeves, 1988). The early FQ (e.g., norfloxacin, ofloxacin, pefloxacin, ciprofloxacin, or enrofloxacin) achieved higher serum levels and showed potent activity against Gram-negative bacteria, several Gram-positive bacteria (such as Staphylococcus aureus), and intracellular bacteria. In addition, ciprofloxacin is active against Pseudomonas aeruginosa. Newer FQ (third generation quinolones) were subsequently developed and presented increased activity toward Gram-positive bacteria, in particularly to Streptococcus pneumoniae (e.g., sparfloxacin, levofloxacin, or moxifloxacin), and potent activity against anaerobic bacteria (e.g., trovafloxacin, gatifloxacin, or gemifloxacin; Van Bambeke et al., 2005).

Even if the main factors leading to resistance to quinolones and FQ related to chromosomal mutations in the drug target genes, the discovery during the last decade of a series of plasmid-encoded resistance mechanisms has contributed to speculate about the origin and enhancing factors of that transferable resistance. In particular, the interplay between an environmental and animal source on one side, and the human clinical pathogens on the other side (in which the emergence of resistance to quinolones is a matter of fact) remains to be further explored and understood.

That review aims to present some of the current available data from which speculations can be established.

\section{MECHANISM OF OUINOLONE ACTION}

The targets of quinolone molecules are the type II topoisomerases: DNA gyrase (topoisomerase II) and DNA topoisomerase IV (Drlica and Zhao, 1997). As opposed to type I topoisomerases that transiently cleave one strand of the DNA double helix, type II topoisomerases break transiently both strands of a duplex and pass another double-helical segment through the break by ATP 
hydrolysis (Drlica and Zhao, 1997; Hawkey, 2003). The DNA gyrase introduces negative supercoils into DNA whereas topoisomerase IV exhibits a potent decatenation activity. Those enzymes are essential for bacterial growth by controlling the topological status of the chromosomal DNA to facilitate replication, transcription, recombination, and DNA repair (Drlica and Zhao, 1997; Hawkey, 2003). The DNA gyrase and the DNA topoisomerase IV are the main targets of quinolones in Gram-negatives and Grampositives, respectively. Quinolones inhibit the activity of type II topoisomerases by trapping these enzymes on DNA as drugenzyme-DNA complexes. Ternary complex formation is responsible for inhibition of bacterial growth (bacteriostatic action) by a rapid inhibition of DNA synthesis and a slower inhibition of RNA synthesis (Drlica and Zhao, 1997; Hawkey, 2003). Eventhough these drug-enzyme-DNA complexes block cell growth, they are not directly responsible for the lethal effect of quinolones. Indeed, bactericidal activity is due to the releasing of double-stranded DNA breaks from those complexes, but the detailed mechanism of action of quinolones still needs to be fully understood.

\section{CHROMOSOME-ENCODED RESISTANCE}

Resistance to quinolones in Enterobacteriaceae most commonly results from the accumulation of mutations primarily in DNA gyrase (GyrA) then in topoisomerase IV (ParC; Hooper, 2000; Ruiz, 2003; Hopkins et al., 2005; Jacoby, 2005). Alterations in GyrA of E. coli predominantly occur within the N-terminus of the protein in the so-called quinolone resistance determining region (QRDR) located between amino acids Ala67 and Gln106. Mutations appear most frequently at codons Ser83 and Asp87, which are located near the active sites of enzyme (Tyr122). In addition, quinolone resistance can be associated with a decreased membrane permeability and/or an overexpression of efflux pump systems (Hooper, 2000; Hopkins et al., 2005).

\section{PLASMID-MEDIATED RESISTANCE}

Although considered as impossible due to the plasmid curing effect of quinolones (Courvalin, 1990), plasmid-mediated quinolone resistance (PMQR) was first reported in 1998 from a Klebsiella pneumoniae isolate in the USA (Munshi et al., 1987). Indeed, a plasmid-mediated resistance to nalidixic acid in Shigella dysenteriae has been reported previously in 1987 (Munshi et al., 1987), but the reality of this phenomenon was later rejected (Courvalin, 1990). To date, several PMQR mechanisms have been identified: Qnr proteins, the aminoglycoside acetyltransferase AAC $\left(6^{\prime}\right)-\mathrm{Ib}-\mathrm{cr}$, and the efflux pumps QepA and OqxAB.

\section{Onr PROTEINS}

\section{Qnr structure and nomenclature}

The first identified PMQR determinant corresponded to the Qnr protein, lately termed QnrA1 (Martinez-Martinez et al., 1998). The corresponding gene was identified on a broad-host range conjugative plasmid recovered from a ciprofloxacin-resistant $K$. pneumoniae isolate (Martinez-Martinez et al., 1998). QnrA1 is a 218-amino-acid protein that belongs to the pentapeptide repeat family, of which more than 500 members are known, distributed in prokaryotics and eukaryotics (Vetting et al., 2006). Those proteins are made of tandemly repeated amino acid sequences with a consensus sequence $[\mathrm{S}, \mathrm{T}, \mathrm{A}$, or $\mathrm{V}][\mathrm{D}$ or $\mathrm{N}][\mathrm{L}$ or $\mathrm{F}][\mathrm{S}, \mathrm{T}$, or $\mathrm{R}][\mathrm{G}]$ (Vetting et al., 2006). Six other QnrA variants (QnrA2 to QnrA7) have been identified, and differ from QnrA1 by a few amino acid substitutions (Jacoby et al., 2008).

Four distantly related Qnr-like determinants belonging to the pentapeptide repeat family have also been identified in Enterobacteriaceae: QnrB, QnrC, QnrD, and QnrS (Hata et al., 2005; Jacoby et al., 2006; Cavaco et al., 2009; Wang et al., 2009). To date, there are 42 QnrB variants, 1 QnrC, 1 QnrD, and 5 QnrS (http://www.lahey.org/qnrStudies/). QnrB1, QnrC1, and QnrS1 share 40, 60, 47, and 59\% amino acid identity with QnrA1, respectively.

In addition, QnrVC-like proteins have been identified in Vibrio cholerae, sharing 57\% amino acid identity with QnrA1 (Fonseca et al., 2008). Even if the qnrVC genes have been identified as acquired resistance genes, they are not plasmid-located, thus not considered as PMQR genes.

\section{Mechanism of action}

QnrA1 shares 20 and 19\% amino acid identity with McbG and MfpA, respectively, two other members of the pentapeptide repeat family both involved in resistance to gyrase inhibitors (Cattoir and Nordmann, 2009). Qnr proteins may supplement resistance to quinolones due to altered quinolone target enzymes, efflux pump activation, or deficiencies in outer-membrane porins (MartinezMartinez et al., 2003; Jeong et al., 2008). In addition, Qnr proteins facilitate selection of quinolone resistance mutants by raising the level at which they can be selected with a frequency more than 100-fold higher (Martinez-Martinez et al., 1998). The presence of Qnr determinants facilitates the selection of low-level of resistance to quinolones due to chromosome-encoded mechanisms. From a clinical point of view, Qnr determinants may increase the mutant prevention concentration (MPC) of ciprofloxacin by more than 10-fold, facilitating recovery of mutants with higher level of resistance to quinolones (Rodriguez-Martinez et al., 2007). Therefore, Qnr-positive isolates may be a favorable background for an in vivo-selection of additional chromosome-borne mechanism(s) of resistance to quinolones after treatment by fluoroquinolones (Poirel et al., 2006).

\section{Epidemiology of Qnr determinants}

Qnr in human clinical isolates. All types of Qnr determinants have been identified worldwide in many different enterobacterial species but mostly in K. pneumoniae, Enterobacter spp., E. coli, and Salmonella enterica from community and nosocomial isolates (Rodríguez-Martínez et al., 2011). Their overall prevalence may range from 0.2 to up to $94 \%$ depending on selection criteria of studied strains (resistance to ceftazidime, nalidixic acid, FQs,. . .; Strahilevitz et al., 2009; Rodríguez-Martínez et al., 2011). The prevalence of $q n r B$ genes seems to be overall higher than that of the other $q n r$ genes. However, the $q n r S$ genes are very frequently identified in Salmonella sp., suggesting that they could represent a significant resistance trait along the food chain. For instance, a recent international survey (13 European countries) identified a qnrS gene in $10 \%$ of the Salmonella sp. collection (Veldman et al., 2011).

Very few studies have been performed to evaluate the prevalence of the $q n r C$ and $q n r D$ genes since those genes have been recently 
identified. However, the qnrC has been identified from a Proteus mirabilis isolate from China, and its prevalence seems to be very low, at least in China (Wang et al., 2009). The qnrD gene has been identified in 22 out of 1215 Salmonella isolates obtained from different European countries, being either of human or animal isolates (Veldman et al., 2011).

Qnr in animal isolates. QnrS1 was first identified from a transferable plasmid carried by a clinical isolate of Shigella flexneri $2 \mathrm{~b}$ as a source of a foodborne outbreak in Aichi prefecture, Japan (Hata et al., 2005). As described for the qnrA1 gene, the qnrS1 gene has been identified from several enterobacterial isolates (particularly in Salmonella spp.) in many countries. It has been identified in porcine E. coli (Szmolka et al., 2011) in Hungary, in equine E. coli in Czech Republic (Dolejska et al., 2011), and in poultry E. coli in China (Yue et al., 2011). The qnrS2 gene was identified in a single non-Typhi Salmonella clinical isolate from the USA (Gay et al., 2006). Finally, the qnrS3 variant has been identified in a single veterinary clinical E. coli isolate from China (GenBank accession no. EU077611).

In an interesting study including 1215 Salmonella and 333 E. coli isolates, six variants of $q n r B$ were identified from 138 q $n r B$-positive isolates, most of them being obtained from turkeys (Veldman et al., 2011). The qnrD gene was identified in 22 Salmonella of eight different serovars, being mostly identified in Spain but also in Italy.

Whereas there is so far no report of $q n r A$-like genes in nonenterobacterial species, $q n r B$ - and $q n r S$-like genes have been identified for instance in Pseudomonas fluorescens and Aeromonas spp. isolates, respectively (Ahmed et al., 2007; Cattoir et al., 2008b; Sanchez-Cespedes et al., 2008). Interestingly, qnrS and mostly $q n r B$ genes were identified from zoo animals, mostly including reptiles (Ahmed et al., 2007).

Qnr determinants in aquatic environments. Overall, the qurStype genes seem to be the most commonly identified acquired qnr genes in the environment. They have been mainly identified from waterborne species, and in particular Aeromonas spp. The $q n r S 2$ gene was identified from a mobilizable IncQ-related plasmid (pGNB2) isolated from an activated sludge bacterial community of a wastewater treatment plant in Germany (Bonemann et al., 2006), in two strains of Aeromonas spp. (Aeromonas punctata and A. media) isolates from the Seine river in France (Cattoir et al., 2007b), and lately in a single clinical Aeromonas veronii isolate from Spain (Sanchez-Cespedes et al., 2008). In Italy, a Citrobacter freundii strain producing the ESBL TEM-116 was recovered from a sewage effluent (Forcella et al., 2010). This ESBL gene was encoded on a plasmid that co-harbored the qnrB9 gene. This constitutes one of the few example showing the occurrence of a $q n r$ gene from an enterobacterial isolate recovered from the environment.

The environmental species that have been found to carry $q n r$ genes were mainly Aeromonas spp. or Vibrio spp. In China, an A. punctata strain recovered from a wastewater sample in the Shandong province carried the qnrVC4 gene on a plasmid (Xia et al., 2010). That strain was resistant to nalidixic acid but susceptible to fluoroquinolones.

\section{Mobile genetic vehicles}

All the $q n r$ genes have been identified on plasmids that vary in size ranging from ca. 7 to $320 \mathrm{~kb}$ (Cattoir and Nordmann, 2009; Strahilevitz et al., 2009) Those plasmids, and especially the $q n r A$ - and qnrB-positive ones, often harbor other antibiotic resistance genes conferring resistance to $\beta$-lactams, aminoglycosides, chloramphenicol, tetracycline, sulfonamides, trimethoprim, and rifampin.

The qnrA-like genes are usually dentified as part of complex sull-type class 1 integrons, that exhibit duplicated $3^{\prime}$-conserved sequences $\left(3^{\prime}-\mathrm{CS}\right)$ containing the qacE $\Delta 1$ and sull genes. Immediately upstream of qnrA genes, the orf513 gene which constitutes the transposase gene of insertion sequence ISCR 1 is systematically identified (Toleman et al., 2006). The qnrB-like genes have been associated with either the orf1005 gene encoding a putative transposase for qnrB1 (Jacoby et al., 2006), the ISCR1 element for qnrB2 (Garnier et al., 2006; Jacoby et al., 2006; Minarini et al., 2008), qnrB4 (Cattoir et al., 2007b; Hu et al., 2008), qnrB10 (Quiroga et al., 2007), and qnrB12 (Kehrenberg et al., 2008), or an ISEcp1 element for $q n r B 19$ (Cattoir et al., 2008a). Although qnrS-like genes are not embedded in sull-type integrons, two different genetic environments have been described, with the qnrS1 genes being identified in association with Tn3-like transposon structures or the insertion sequence ISEcl2 (Poirel et al., 2007), and the qnrS2 gene being part of a transposon-like structure, named mobile insertion cassette (MIC), and inserted in an ORF coding for a zinc metalloprotease (MpR) in Aeromonas spp. (Cattoir et al., 2008b; Sanchez-Cespedes et al., 2008).

\section{The qnr genes originate from environmental species}

By screening for a collection of 48 Gram-negative clinical and environmental bacterial species (Enterobacteriaceae, Aeromonadaceae, Pseudomonadaceae, Xanthomonadaceae, Moraxellaceae, and Shewanellaceae), the origin of the qnrA gene was identified as being the chromosome of Shewanella algae (Poirel et al., 2005b). Indeed, three QnrA-like determinants (termed QnrA3, QnrA4, and QnrA5) have been identified in S. algae, and differ by a few amino acid substitutions from QnrA1. S. algae is widely distributed in aquatic environments and rarely involved in human infections. As opposed to what it has been described for the plasmid-mediated qnrA1 gene, the chromosomal qnrA-like genes were not associated with the ISCR1 element in the chromosome of S. algae (Poirel et al., 2005b). Finally, The G + C content (52\%) of the qnrA-like of S. algae matched exactly that of the genome of S. algae (Poirel et al., 2005b).

It has been shown that Vibrio splendidus is a source of QnrSlike determinants since chromosomal-encoded Qnr-like proteins shared about 84 and $88 \%$ amino acid identity with the plasmidmediated determinants QnrS1 and QnrS2, respectively (Cattoir et al., 2007a). In addition, the $\mathrm{G}+\mathrm{C}$ contents of $q n r S$-like genes from $V$. splendidus (ca. 45\%) are close to those of qnrS1 and qnrS2 (ca. 44\%). Although the exact progenitor species of the plasmid-encoded QnrS determinant remains unknown, the bacterial species should be closely related to V. splendidus and likely waterborne.

Recently, the progenitor of the qnrB-like genes was identified to be Citrobacter spp. which are enterobacterial species known to 
be widely present in the aquatic environment, being either human commensal bacteria or opportunistic pathogens depending on the species (Jacoby et al., 2011).

Noteworthy, it has been shown that some bacterial species belonging to the Vibrionaceae family (such as Vibrio vulnificus, Vibrio parahaemolyticus, or Photobacterium profundum) also possess intrinsically chromosome-encoded Qnr-like determinants (sharing 40-67\% identity with the plasmid-mediated Qnr determinants) and conferring resistance to quinolones (Poirel et al., 2005a). That means that those waterborne species may also constitute potential sources of emerging PMQR genes.

Several Qnr-like pentapeptide repeat proteins have been identified in the chromosome of Gram-positive bacteria (Enterococcus faecalis, Enterococcus faecium, Listeria monocytogenes, Clostridium perfringens, Clostridium difficile, Bacillus cereus, and Bacillus subtilis; Arsene and Leclercq, 2007; Rodriguez-Martinez et al., 2008). Amino acid sequences of these Qnr-like proteins are identical from 16 to $22 \%$ with the PMQR determinants QnrA1, QnrB1, and QnrS1 (Rodriguez-Martinez et al., 2008). Similarly, those Gram-positive species could also constitute a reservoir for Qnrlike although none of these genes has been yet identified as plasmid-located determinants.

\section{AMINOGLYCOSIDE ACETYLTRANSFERASE AAC(6')-lb-cr}

The AAC $\left(6^{\prime}\right)$-Ib-cr enzyme is a PMQR determinant that has been discovered from qnrA-positive E. coli from Shanghai, China (Robicsek et al., 2006). The aac $\left(6^{\prime}\right)-I b-c r$ (for ciprofloxacin resistance) gene encodes a variant of the widespread aminoglycoside acetyltransferase $\mathrm{AAC}\left(6^{\prime}\right)$-Ib usually responsible for resistance to kanamycin, tobramycin, and amikacin (Strahilevitz et al., 2009). This variant possesses two substitutions at codons 102 (Trp $\rightarrow$ Arg) and 179 (Asp $\rightarrow$ Tyr) compared to the wild-type AAC $\left(6^{\prime}\right)-\mathrm{Ib}$, both mutations seem to be required to confer reduced susceptibility to several FQ molecules (Robicsek et al., 2006). The protein AAC(6')-Ib-cr is able to acetylate kanamycin, tobramycin, and amikacin, but also ciprofloxacin conferring slightly higher MIC values (twofold to fourfold increase). Nevertheless, it acetylates more efficiently aminoglycosides than ciprofloxacin. Since acetylation occurs at the amino nitrogen on the piperazinyl substituent, only FQs harboring an unsubstituted piperazinyl group (such as ciprofloxacin and norfloxacin) are substrates of AAC $\left(6^{\prime}\right)$-Ib-cr (Robicsek et al., 2006). Although the $\operatorname{aac}\left(6^{\prime}\right)-\mathrm{Ib}-\mathrm{cr}$ gene by itself confers low-level resistance to certain FQs, it may facilitate survival of target-site mutants with a 10-fold increase of their MPC (Cattoir and Nordmann, 2009).

The overall prevalence of $a a c\left(6^{\prime}\right)-I b-c r$ may range from 0.4 to up to $34 \%$ depending on the studied human clinical strains (Robicsek et al., 2006). This gene has been reported mostly from E. coli and K. pneumoniae clinical isolates. However, it has also been identified in Aeromonas spp. collected in 2006 from feces of zoo animals in Japan (Ahmed et al., 2007). Recently, it has been identified in Salmonella spp. recovered from chickens in Japan, and in E. coli of poultry origin in Spain or of pig origin in China (Liu et al., 2011; Soufi et al., 2011; Du et al., 2012). Since this gene seems to be geographically widespread, stable over the time, and equally prevalent in ciprofloxacin-susceptible and -resistant strains (Park et al., 2006), its significance remains debatable. Its occurrence could also result from human contamination, as suggested with a study from Gibson et al. (2010) identifying this gene in companion animals.

The $\operatorname{aac}\left(6^{\prime}\right)-I b$ - $c r$ gene has been identified as a form a gene cassette into sull-type class 1 integrons, and has been identified both among ESBL-positive and ESBL-negative enterobacterial isolates (Cattoir and Nordmann, 2009). Its occurrence in animals and in the environment is likely frequent, but extensive surveys are still required to better evaluate their prevalence in environmental habitats.

\section{EFFLUX PUMP OepA}

Whereas efflux pumps are chromosome-encoded, a novel PMQR determinant, qepA (for quinolone efflux pump), has been identified in E. coli human clinical isolates from Japan and Belgium (Perichon et al., 2007; Yamane et al., 2007). This gene encodes a 511 -amino-acid deduced protein $(53 \mathrm{kDa})$ that shares significant identity with various 14-transmembrane-segment (14-TMS) putative efflux pump belonging to the major facilitator superfamily (MFS) of proton-dependent transporters (Perichon et al., 2007; Yamane et al., 2007). This protein confers significant decreased susceptibility to the hydrophilic quinolones (e.g., norfloxacin, ciprofloxacin, and enrofloxacin) with an 8- to 32-fold increase of MICs as compared to a wild-type susceptibility profile (Yamane et al., 2007). On the opposite, QepA protein does not significantly modify MICs of moderately hydrophilic (e.g., pefloxacin, sparfloxacin, levofloxacin, moxifloxacin) and hydrophobic (e.g., nalidixic acid) quinolones (Perichon et al., 2007; Yamane et al., 2007).

The occurrence of QepA among human clinical isolates seems to be quite limited according to the few studies that have been conducted on this subject worldwide. However, its occurrence in animals might be significant. A study performed on E. coli isolates from pigs in China showed that 28 (58.3\%) out of 48 $16 \mathrm{~S}$ rRNA methylase RmtB-producing $E$. coli isolates were qepApositive suggesting a strong linkage between qepA and $r m t B$ genes (Liu et al., 2008). RmtB confers resistance to all aminoglycosides (except streptomycin) by decreasing the affinity of the ribosome for the antibiotic after N7-methylation at the G1405 within the 16S rRNA (Perichon et al., 2007).

Other E. coli isolates from pigs in China have been reported as co-expressing the $q e p A, q \eta r S 2$, and $a a c\left(6^{\prime}\right)-I b-c r$ genes (Liu et al., 2008). This co-expression of several PMQR determinants may facilitate the selection of mutants under selective pressure of antimicrobial agents. QepA-producing enterobacterial isolates were also identified from pets in China (Deng et al., 2011). In Nigeria, an E. coli strain recovered from chicken co-harbored a $q e p A$ and a $q n r B$ gene (Fortini et al., 2011).

The natural reservoir of qepA remains unknown. However, it may be Actinomycetales species since QepA had significant amino acid identity with likely membrane transporters of the members of the order of Actinomycetales (such as Streptomyces globisporus, Streptomyces coelicolor, Nocardia farcinica, or Polaromonas spp.), and its high GC\% content (72\%) is compatible with this origin.

\section{EFFLUX PUMP OqxAB}

The OqxAB multidrug resistance mechanism was initially identified from E. coli strains recovered from swine manure (Hansen 
et al., 2004). The identified plasmid harbored the oqxA and oqxB genes that are similar to genes encoding resistance-nodulationcell-division efflux systems. That plasmid conferred resistance to olaquindox that is a veterinary growth promoter. Then, it was shown to mediate resistance to other molecules, such as chloramphenicol, nalidixic acid, and ciprofloxacin (Hansen et al., 2007). In Denmark, a retrospective study showed that nine out of 156 E. coli strains isolated from pigs were positive for the oq $x A$ gene (Hansen et al., 2005). Recently, a Chinese study showed that $39 \%$ of the $E$. coli isolates recovered from sows, piglets, weaners, and boars in swine farms, and chicken in chicken farms harbored the oq $x A B$ gene (Zhao et al., 2010). An OqxAB-positive E. coli strain was also identified from a liver sample of a diseased chicken in China (Liu et al., 2008). Interestingly, another Chinese study reported a series of $K$. pneumoniae isolates in which the $o q x A B$ genes were actually chromosomally located (Kim et al., 2009).

\section{DISCUSSION}

The discovery of a series of PMQR determinants within the last 10 years further raised out a novel issue regarding resistance to quinolones. Indeed, whereas such resistance was supposed to be only vertically transmitted, the occurrence of those PMQR encoding genes show that it may be also horizontally mediated. Noteworthy, and even if the first research interests focused on the impact and relevance of PMQR genes among human clinical isolates, subsequent studies rapidly showed that they were also of main concern in animal and environmental strains. Such observation raises out several questions: are there relationships between

\section{REFERENCES}

Ahmed, A. M., Motoi, Y., Sato, M., Maruyama, A., Watanabe, H., Fukumoto, Y., and Shimamoto, T. (2007). Zoo animals as reservoirs of gramnegative bacteria harboring integrons and antimicrobial resistance genes. Appl. Environ. Microbiol. 73, 6686-6690.

Arsene, S., and Leclercq, R. (2007). Role of a qnr-like gene in the intrinsic resistance of Enterococcus faecalis to fluoroquinolones. Antimicrob. Agents Chemother. 51, 3254-3258.

Ball, P. (2000). Quinolone generations: natural history or natural selection? J. Antimicrob. Chemother. 46(Suppl. T1), 17-24.

Bonemann, G., Stiens, M., Puhler, A., and Schluter, A. (2006). Mobilizable IncQ-related plasmid carrying a new quinolone resistance gene, qnrS2, isolated from the bacterial community of a wastewater treatment plant. Antimicrob. Agents Chemother. 50, 3075-3080.

Cattoir, V., and Nordmann, P. (2009). Plasmid-mediated quinolone resistance in gram-negative bacterial species: an update. Curr. Med. Chem. 16, 1028-1046.

Cattoir, V., Nordmann, P., SilvaSanchez, J., Espinal, P., and Poirel,

quinolones in the environment that are poorly biodegraded and the prevalence of those resistance mechanisms? Are those resistance mechanisms really new and emerging? Which is the extend of the interplay between the situation observed in the environment and the current clinical concerns?

The heavy use of quinolones in animals and in particular in fish farming might likely have played a role in the selection of some resistance mechanisms. This may have impacted the fauna itself, and as a consequence the environment through contamination of aquatic habitats, but that speculation remains debatable. A recent study showed that there was no correlation between the occurrence of FQ-resistant bacteria in aquatic environments and the FQ contamination in Vietnam and Thailand (Takasu et al., 2011). However, the authors designed their study by selecting FQ-resistant bacteria with high level of resistance (more than $16 \mathrm{mg} / \mathrm{l}$ ), that is not a correct criteria when focusing on PMQR only conferring decreased susceptibility to FQ.

The fact that most if not all PMQR encoding genes originate from bacterial species that are naturally present in the environment, and in particular in the aquatic one, likely suggests that this latter may represent the main source of the problem. This is indeed probable that genetic events leading to the mobilization of the resistance gene from the natural reservoir (the progenitor or the donor) to the recipient (the target plasmid or the target strain) occur in those environments where the donor is numerous.

\section{ACKNOWLEDGMENTS}

This work was funded by a grant from the INSERM (U914).

Courvalin, P. (1990). Plasmid-mediated 4-quinolone resistance: a real or apparent absence? Antimicrob. Agents Chemother. 34, 681-684.

Deng, Y., He, L., Chen, S., Zheng, H. Zeng, Z., Liu, Y., Sun, Y., Ma, J., Chen, Z., and Liu, J. H. (2011). F33:A-:B- and F2:A-:B- plasmids mediate dissemination of $r m t B$ $b l a_{\text {CTX-M-9 }}$ group genes and $r m t B$ $q е p A$ in Enterobacteriaceae isolates from pets in China. Antimicrob. Agents Chemother. 55, 4926-4929.

Dolejska, M., Duskova, E., Rybarikova, J., Janoszowska, D., Roubalova, E., Dibdakova, K., Maceckova, G., Kohoutova, L., Literak, I., Smola, J., and Cizek, A. (2011). Plasmids carrying bla $a_{\mathrm{CTX}-\mathrm{M}-1}$ and $q n r$ genes in Escherichia coli isolates from an equine clinic and a horseback riding centre. J. Antimicrob. Chemother. 66, 757-764.

Drlica, K., and Zhao, X. (1997). DNA gyrase, topoisomerase IV, and the 4-quinolones. Microbiol. Mol. Biol. Rev. 61, 377-392.

Du, X. D., Li, D. X., Hu, G. Z., Wang, Y., Shang, Y. H., Wu, C. M., Liu, H. B., and Li, X. S. (2012). Tn1548associated armA is co-located with $q n r B 2, a a c\left(6^{\prime}\right)-I b-c r$ and $b l a_{\mathrm{CTX}-\mathrm{M}-3}$ on an IncFII plasmid in a Salmonella enterica subsp. enterica serovar
Paratyphi B strain isolated from chickens in China. J. Antimicrob. Chemother. 67, 246-248.

Fonseca, E. L., Dos Santos Freitas, F., Vieira, V. V., and Vicente, A. C. (2008). New qnr gene cassettes associated with superintegron repeats in Vibrio cholerae O1. Emerging Infect. Dis. 14, 1129-1131.

Forcella, C., Pellegrini, C., Celenza, G., Segatore, B., Calabrese, R., Tavio M. M., Amicosante, G., and Perilli, M. (2010). QnrB9 in association with TEM-116 extended-spectrum ß-lactamase in Citrobacter freundii isolated from sewage effluent: first report from Italy. J. Chemother. 22, 243-245.

Fortini, D., Fashae, K., GarcíaFernández, A., Villa, L., and Carattoli, A. (2011). Plasmidmediated quinolone resistance and $\beta$-lactamases in Escherichia coli from healthy animals from Nigeria. J. Antimicrob. Chemother. 66, 1269-1272.

Garnier, F., Raked, N., Gassama, A., Denis, F., and Ploy, M. C. (2006). Genetic environment of quinolone resistance gene qnrB2 in a complex sull-type integron in the newly described Salmonella enter ica serovar Keurmassar. Antimicrob. Agents Chemother. 50, 3200-3202. 
Gay, K., Robicsek, A., Strahilevitz, J., Park, C. H., Jacoby, G., Barrett, T. J., Medalla, F., Chiller, T. M., and Hooper, D. C. (2006). Plasmid-mediated quinolone resistance in non-Typhi serotypes of Salmonella enterica. Clin. Infect. Dis. 43, 297-304.

Gibson, J. S., Cobbold, R. N., Heisig, P., Sidjabat, H. E., Kyaw-Tanner, M. T., and Trott, D. J. (2010). Identification of Qnr and AAC (6' $)$-1b-cr plasmidmediated fluoroquinolone resistance determinants in multidrugresistant Enterobacter spp. isolated from extraintestinal infections in companion animals. Vet. Microbiol. 143, 329-336.

Hansen, L. H., Jensen, L. B., Sørensen, H. I., and Sørensen, S. J. (2007). Substrate specificity of the OqxAB multidrug resistance pump in Escherichia coli and selected enteric bacteria. J. Antimicrob. Chemother. 60, 145-147.

Hansen, L. H., Johannesen, E., Burmølle, M., Sørensen, A. H., and Sørensen, S. J. (2004). Plasmidencoded multidrug efflux pump conferring resistance to olaquindox in Escherichia coli. Antimicrob. Agents Chemother. 48, 3332-3337.

Hansen, L. H., Sørensen, S. J., Jørgensen, H. S., and Jensen, L. B. (2005). The prevalence of the OqxAB multidrug efflux pump amongst olaquindoxresistant Escherichia coli in pigs. Microb. Drug Resist. 11, 378-382.

Hata, M., Suzuki, M., Matsumoto, M., Takahashi, M., Sato, K., Ibe, S., and Sakae, K. (2005). Cloning of a novel gene for quinolone resistance from a transferable plasmid in Shigella flexneri 2b. Antimicrob. Agents Chemother. 49, 801-803.

Hawkey, P. M. (2003). Mechanisms of quinolone action and microbial response. J. Antimicrob. Chemother. 51(Suppl. 1), 29-35.

Hooper, D. C. (2000). Mechanisms of action and resistance of older and newer fluoroquinolones. Clin. Infect. Dis. 31(Suppl. 2), 24-28.

Hopkins, K. L., Davies, R. H., and Threlfall, E. J. (2005). Mechanisms of quinolone resistance in Escherichia coli and Salmonella: recent developments. Int. J. Antimicrob. Agents 25, 358-373.

Hu, F. P., Xu, X. G., Zhu, D. M., and Wang, M. G. (2008). Coexistence of qnrB4 and qnrS1 in a clinical strain of Klebsiella pneumoniae. Acta Pharmacol. Sin. 29, 320-324.

Jacoby, G., Cattoir, V., Hooper, D., Martinez-Martinez, L., Nordmann, P., Pascual, A., Poirel, L., and Wang, M. (2008). qnr gene nomenclature.
Antimicrob. Agents Chemother. 52, 2297-2299.

Jacoby, G. A. (2005). Mechanisms of resistance to quinolones. Clin. Infect. Dis. 15, 41(Suppl. 2), S120-S126.

Jacoby, G. A., Griffin, C. M., and Hooper, D. C. (2011). Citrobacter spp. as a source of $q n r B$ alleles. Antimicrob. Agents Chemother. 55, 4979-4984.

Jacoby, G. A., Walsh, K. E., Mills, D. M., Walker, V. J., Oh, H., Robicsek, A., and Hooper, D. C. (2006). qnrB, another plasmid-mediated gene for quinolone resistance. Antimicrob. Agents Chemother. 50, 1178-1182.

Jeong, J. Y., Kim, E. S., Choi, S. H., Kwon, H. H., Lee, S. R., Lee, S. O., Kim, M. N., Woo, J. H., and Kim, Y. S. (2008). Effects of a plasmid-encoded qnrA1 determinant in Escherichia coli strains carrying chromosomal mutations in the acrAB efflux pump genes. Diagn. Microbiol. Infect. Dis. 60, 105-107.

Kehrenberg, C., Friederichs, S., de Jong, A., and Schwarz, S. (2008). Novel variant of the $q n r B$ gene, $q n r B 12$, in Citrobacter werkmanii. Antimicrob. Agents Chemother. 52, 1206-1207.

Kim, H. B., Wang, M., Park, C. H., Kim, E. C., Jacoby, G. A., and Hooper, D. C. (2009). oq $x A B$ encoding a multidrug efflux pump in human clinical isolates of Enterobacteriaceae. Antimicrob. Agents Chemother. 53, 3582-3584.

Lesher, G. Y., Froelich, E. J., Gruett, M. D., Bailey, J. H., and Brundage, R. P. (1962) 1,8 Naphthyridine derivatives. A new class of chemotherapeutic agents. J. Med. Pharm. Chem. 91, 1063-1065.

Liu, B. T., Wang, X. M., Liao, X. P., Sun, J., Zhu, H. Q., Chen, X. Y., and Liu, Y. H. (2011). Plasmid-mediated quinolone resistance determinants $o q x A B$ and $a a c\left(6^{\prime}\right)-I b-c r$ and extended-spectrum $\beta$-lactamase gene $b l a_{\mathrm{CTX}-\mathrm{M}-24}$ co-located on the same plasmid in one Escherichia coli strain from China. J. Antimicrob. Chemother. 66, 1638-1639.

Liu, J. H., Deng, Y. T., Zeng, Z. L., Gao, J. H., Chen, L., Arakawa, Y., and Chen, Z. L. (2008). Coprevalence of plasmid-mediated quinolone resistance determinants QepA, Qnr, and $\mathrm{AAC}\left(6^{\prime}\right)-\mathrm{Ib}-\mathrm{cr}$ among $16 \mathrm{~S}$ rRNA methylase RmtB-producing Escherichia coli isolates from pigs. Antimicrob. Agents Chemother. 52, 2992-2993.

Martinez-Martinez, L., Pascual, A., Garcia, I., Tran, J., and Jacoby, G. A. (2003). Interaction of plasmid and host quinolone resistance. J. Antimicrob. Chemother. 51, 1037-1039.
Martinez-Martinez, L., Pascual, A., and Jacoby, G. A. (1998). Quinolone resistance from a transferable plasmid. Lancet 351, 797-799.

Minarini, L. A., Poirel, L., Cattoir, V., Darini, A. L., and Nordmann, P. (2008). Plasmid-mediated quinolone resistance determinants among enterobacterial isolates from outpatients in Brazil. J. Antimicrob. Chemother. 62, 474-478.

Munshi, M. H., Sack, D. A., Haider, K. Ahmed, Z. U., Rahaman, M. M., and Morshed, M. G. (1987). Plasmidmediated resistance to nalidixic acid in Shigella dysenteriae type 1. Lancet 2, 419-421.

Park, C. H., Robicsek, A., Jacoby, G. A., Sahm, D., and Hooper, D. C. (2006). Prevalence in the United States of $a a c\left(6^{\prime}\right)-I b-c r$ encoding a ciprofloxacin-modifying enzyme. Antimicrob. Agents Chemother. 50, 3953-3955.

Paton, J. H., and Reeves, D. S. (1988) Fluoroquinolone antibiotics. Microbiology, pharmacokinetics and clinical use. Drugs 36, 193-228.

Perichon, B., Courvalin, P., and Galimand, M. (2007). Transferable resistance to aminoglycosides by methylation of G1405 in 16S rRNA and to hydrophilic fluoroquinolones by QepA-mediated efflux in Escherichia coli. Antimicrob. Agents Chemother. 51, 2464-2469.

Poirel, L., Cattoir, V., Soares, A., Soussy, C.-J., and Nordmann, P. (2007). Novel Ambler class A B-lactamase LAP-1 and its association with the plasmid-mediated quinolone resistance determinant QnrS1. Antimicrob. Agents Chemother. 51, 631-637.

Poirel, L., Liard, A., RodriguezMartinez, J. M., and Nordmann, P. (2005a). Vibrionaceae as a possible source of Qnr-like quinolone resistance determinants. J. Antimicrob. Chemother. 56, 1118-1121.

Poirel, L., Rodriguez-Martinez, J. M., Mammeri, H., Liard, A., and Nordmann, P. (2005b). Origin of plasmid-mediated quinolone resistance determinant QnrA Antimicrob. Agents Chemother. 49, 3523-3525.

Poirel, L., Pitout, J. D., Calvo, L., Rodriguez-Martinez, J. M., Church, D., and Nordmann, P. (2006). In vivo selection of fluoroquinoloneresistant Escherichia coli isolates expressing plasmid-mediated quinolone resistance and expandedspectrum B-lactamase. Antimicrob. Agents Chemother. 50, 1525-1527.

Quiroga, M. P., Andres, P., Petroni, A. Soler Bistue, A. J., Guerriero, L.,
Vargas, L. J., Zorreguieta, A., Tokumoto, M., Quiroga, C., Tolmasky, M. E., Galas, M., and Centron, D. (2007). Complex class 1 integrons with diverse variable regions, including $a a c\left(6^{\prime}\right)-I b-c r$, and a novel allele, qnrB10, associated with ISCR 1 in clinical enterobacterial isolates from Argentina. Antimicrob. Agents Chemother. 51, 4466-4470.

Robicsek, A., Strahilevitz, J., Jacoby, G. A., Macielag, M., Abbanat, D., Park, C. H., Bush, K., and Hooper, D. C. (2006). Fluoroquinolone-modifying enzyme: a new adaptation of a common aminoglycoside acetyltransferase. Nat. Med. 12, 83-88.

Rodríguez-Martínez, J. M., Cano, M. E., Velasco, C., Martínez-Martínez, L., and Pascual, A. (2011). Plasmidmediated quinolone resistance: an update. J. Infect. Chemother. 17, 149-182.

Rodriguez-Martinez, J. M., Velasco, C., Briales, A., Garcia, I., Conejo, M. C., and Pascual, A. (2008). Qnrlike pentapeptide repeat proteins in gram-positive bacteria. J. Antimicrob. Chemother. 61, 1240-1243.

Rodriguez-Martinez, J. M., Velasco, C., Garcia, I., Cano, M. E., MartinezMartinez, L., and Pascual, A. (2007). Mutant prevention concentrations of fluoroquinolones for Enterobacteriaceae expressing the plasmidcarried quinolone resistance determinant qnrAl. Antimicrob. Agents Chemother. 51, 2236-2239.

Ruiz, J. (2003). Mechanisms of resistance to quinolones: target alterations, decreased accumulation and DNA gyrase protection. J. Antimicrob. Chemother. 51, 1109-1117.

Sanchez-Cespedes, J., Blasco, M. D., Marti, S., Alba, V., Alcaide, E., Esteve, C., and Vila, J. (2008). Plasmidmediated QnrS2 determinant from a clinical Aeromonas veronii isolate. Antimicrob. Agents Chemother. 52, 2990-2991.

Soufi, L., Sáenz, Y., Vinué, L., Abbassi, M. S., Ruiz, E., Zarazaga, M., Ben Hassen, A., Hammami, S., and Torres, C. (2011). Escherichia coli of poultry food origin as reservoir of sulphonamide resistance genes and integrons. Int. J. Food Microbiol. 144, 497-502.

Strahilevitz, J., Jacoby, G. A., Hooper, D. C., and Robicsek, A. (2009). Plasmid-mediated quinolone resistance: a multifaceted threat. Clin. Microbiol. Rev. 22, 664-689.

Szmolka, A., Fortini, D., Villa, L., Carattoli, A., Anjum, M. F., and Nagy, B. (2011). First report on IncN plasmid-mediated quinolone resistance gene qnrS1 
in porcine Escherichia coli in Europe. Microb. Drug Resist. 17, 567-573.

Takasu, H., Suzuki, S., Reungsang, A., and Pham, H. V. (2011). Fluoroquinolone (FQ) contamination does not correlate with occurrence of FQ-resistant bacteria in aquatic environments of Vietnam and Thailand. Microbes Environ. 26, 135-143.

Toleman, M. A., Bennett, P. M., and Walsh, T. R. (2006). ISCR elements: novel gene-capturing systems of the 21st century? Microbiol. Mol. Biol. Rev. 70, 296-316.

Van Bambeke, F., Michot, J. M., Van Eldere, J., and Tulkens, P. M. (2005). Quinolones in 2005: an update. Clin. Microbiol. Infect. 11, 256-280.

Veldman, K., Cavaco, L. M., Mevius, D., Battisti, A., Franco, A., Botteldoorn, N., Bruneau, M., PerrinGuyomard, A., Cerny, T., De Frutos Escobar, C., Guerra, B., Schroeter, A., Gutierrez, M., Hopkins, K., Myllyniemi, A. L., Sunde, M., Wasyl,
D., and Aarestrup, F. M. (2011). International collaborative study on the occurrence of plasmid-mediated quinolone resistance in Salmonella enterica and Escherichia coli isolated from animals, humans, food and the environment in 13 European countries. J. Antimicrob. Chemother. 66, 1278-1286.

Vetting, M. W., Hedge, S. S., Fajardo, J. E., Fiser, A., Roderick, S. L., Takiff, H. E., and Blanchard, J. S. (2006). Pentapeptide repeat proteins. Biochemistry $45,1-10$.

Wang, M., Guo, Q., Xu, X., Wang, X., Ye, X., Wu, S., Hooper, D. C., and Wang, M. (2009). New plasmid-mediated quinolone resistance gene, $q n r C$, found in a clinical isolate of Proteus mirabilis. Antimicrob. Agents Chemother. 53, 1892-1897.

Xia, R., Guo, X., Zhang, Y., and Xu, H. (2010). qnrVC-like gene located in a novel complex class 1 integron harboring the ISCR1 element in an Aeromonas punctata strain from an aquatic environment in Shandong Province, China. Antimicrob. Agents Chemother. 54 3471-3474.

Yamane, K., Wachino, J., Suzuki, S., Kimura, K., Shibata, N., Kato, H., Shibayama, K., Konda, T., and Arakawa, Y. (2007). New plasmid-mediated fluoroquinolone efflux pump, QepA, found in an Escherichia coli clinical isolate. Antimicrob. Agents Chemother. 51, 3354-3560.

Yue, L., Chen, X., Li, S., Liao, X., Zhuang, N., Zhang, Y., and Liu, Y. H. (2011) First report of plasmid-mediated quinolone resistance qnrAl gene in Klebsiella pneumoniae isolate of animal origin. Foodborne Pathog. Dis. 8, 565-568.

Zhao, J., Chen, Z., Chen, S., Deng, Y. Liu, Y., Tian, W., Huang, X., Wu, C., Sun, Y., Sun, Y., Zeng, Z., and Liu, J. H. (2010). Prevalence and dissemination of $o q x A B$ in Escherichia coli isolates from animals, farmworkers, and the environment. Antimicrob. Agents Chemother. 54, 4219-4224.
Conflict of Interest Statement: The authors declare that the research was conducted in the absence of any commercial or financial relationships that could be construed as a potential conflict of interest.

Received: 23 December 2011; accepted: 15 January 2012; published online: 02 February 2012.

Citation: Poirel L, Cattoir $V$ and Nordmann P (2012) Plasmid-mediated quinolone resistance; interactions between human, animal, and environmental ecologies. Front. Microbio. 3:24. doi: 10.3389/fmicb.2012.00024

This article was submitted to Frontiers in Antimicrobials, Resistance and Chemotherapy, a specialty of Frontiers in Microbiology.

Copyright (C) 2012 Poirel, Cattoir and Nordmann. This is an open-access article distributed under the terms of the Creative Commons Attribution Non Commercial License, which permits noncommercial use, distribution, and reproduction in other forums, provided the original authors and source are credited. 